\title{
Determination of Ranitidine in Human Plasma by SPE and ESI-LC-MS/MS for Use in Bioequivalence Studies
}

\author{
Karini B. Bellorio, ${ }^{1,2}$ Maria Isabel R. Alves, ${ }^{1}$ and Nelson R. Antoniosi Filho ${ }^{1}$ \\ ${ }^{1}$ Laboratório de Métodos de Extração e Separação (LAMES), Instituto de Química, Universidade Federal de Goiás, \\ Campus Samambaia, CP 131, 74001-970 Goiânia, GO, Brazil \\ ${ }^{2}$ Núcleo Integrado de Farmacocinética da Universidade Federal de Goiás e Instituto Melon de Estudos e Pesquisas/Instituto de Ciências \\ Farmacêuticas, CP 131, 74001-970 Goiânia, GO, Brazil
}

Correspondence should be addressed to Maria Isabel R. Alves; isaribeiroalves@yahoo.com.br

Received 9 November 2012; Accepted 16 December 2012

Academic Editors: J.-F. Jen, J. Millership, and A. Sanches Silva

Copyright ( $) 2013$ Karini B. Bellorio et al. This is an open access article distributed under the Creative Commons Attribution License, which permits unrestricted use, distribution, and reproduction in any medium, provided the original work is properly cited.

A method for determining ranitidine in human plasma by ESI-LC-MS/MS was validated, using propranolol as internal standard. The extraction method used was solid phase extraction (SPE). Chromatographic separation was performed in a Chromolith C18 $(50 \mathrm{~mm} \times 4.6 \mathrm{~mm}$ i.d.) analytical column, which provided good separation of ranitidine and propranolol peaks with an analysis time of 2.5 minutes. Extraction yields of $94.4 \%$ for ranitidine and $89.4 \%$ for the internal standard were obtained. The lower limit of quantification (LLOQ) was $3.00 \mathrm{ng} / \mathrm{mL}$, and limit of detection (LOD) was $0.05 \mathrm{ng} / \mathrm{mL}$, with linearity ranging from 3.00 to $500 \mathrm{ng} / \mathrm{mL}$. The results, thus, showed that this method is suitable for application in bioequivalence studies of ranitidine in human plasma.

\section{Introduction}

The chemical structure of ranitidine hydrochloride (Figure 1) consists of a five-membered furan heterocyclic ring and a nitroethenodiaminic group. The molecular mass of ranitidine hydrochloride is 350.9 daltons $(\mathrm{g} / \mathrm{mol})$, and its molecular formula is $\mathrm{C}_{13} \mathrm{H}_{22} \mathrm{~N}_{4} \mathrm{O}_{3} \mathrm{SHCl}$ corresponding to hydrochloride $\mathrm{N}$ [2-[[[5-[(dimethylamine)methyl)-2-furan] methyl] thio] ethyl]-N'-methyl-nitro2-1,1-ethenodiamine. Ranitidine hydrochloride appears as a crystalline powder, practically odorless and white to light yellow. It is very soluble in water, somewhat soluble in alcohol, and slightly soluble in chloroform. Furthermore, it should be stored in hermetically sealed containers and protected from light [1].

Ranitidine is widely used in the treatment of gastric pathologies, has a chemical structure that partially resembles histamine, and acts primarily as a competitive histamine inhibitor through the $\mathrm{H}_{2}$ receptors $[2,3]$.

Since around two thousand analyses are conducted before bioequivalence studies can be concluded, the search for quick and simple methods to determine drugs in biological matrices has been intense. Thus, several methods for determining ranitidine in human plasma have been reported. Zendelovska and Stafilov [4] developed a method for determining ranitidine and cimetidine in human plasma using HPLC with a diode array detector. In this study, the analysis time was 9 minutes, with a $50.0 \mathrm{ng} / \mathrm{mL}$ limit of detection for ranitidine. Famotidine was used as internal standard. In another study using the same detector, an analysis time of 6.5 minutes was obtained in a C18 column ( $300 \mathrm{~mm} \times 4.6 \mathrm{~mm}$ id, $5 \mu \mathrm{m})$, with a limit of quantification of $20.0 \mathrm{ng} / \mathrm{mL}$ [5].

Methods for analyzing ranitidine in plasma by LCMS/MS have been reported in some studies [6-8]. The limits of quantification ranged from $1.0 \mathrm{ng} / \mathrm{mL}$ to $12.2 \mathrm{ng} / \mathrm{mL}$. However, these methods use the protein precipitation procedure. This has the disadvantage of reducing the useful life of the column due to the presence of compounds that are not precipitates or that use liquid-liquid extraction, which requires large volumes of sample and has a higher limit of quantification. 
<smiles>CNC(NCCSCc1ccc(CN(C)C)o1)=C([O-])[O-]</smiles>

Figure 1: Chemical structure of ranitidine hydrochloride.

Thus, the object of this paper was to develop an analytical methodology for determining ranitidine in human plasma using the solid phase extraction (SPE) technique and high performance liquid chromatography coupled to mass spectrometry (HPLC-MS/MS) in order to develop a fast, highly specific, and repeatable methodology for use in pharmaceutical bioequivalence studies.

\section{Experimental}

2.1. Chemicals and Reagents. Ultrapure water generated by the Millipore Milli-Q Gradient 10 ultrapurification system was used in all processes. HPLC-grade reagents were supplied by Merck. We used the (United Stated Pharmacopeia) USP reference standard for ranitidine hydrochloride (lot $G$ ) and the Brazilian Pharmacopoeia primary standard for propranolol hydrochloride (lot 1005).

\subsection{Instrumentation and Chromatographic Conditions.} Chromatographic analyses were performed on a Shimadzu AD Vp HPLC (Shimadzu, Japan) coupled to a Quattro LC (MS-MS) triple quadrupole mass spectrometer (Micromass, UK) equipped with Z-spray operated in electrospray positive $(\mathrm{ES}+)$ mode, with argon as the collision gas. The system was controlled by MassLynx software version 3.4 for Windows NT. The chromatographic conditions were determined using a Merck Chromolith C18 analytical column $(50 \mathrm{~mm} \times 4.6 \mathrm{~mm}$ i.d. $)$ with a flow rate of $0.5 \mathrm{~mL} / \mathrm{min}$ for a mobile phase consisting of aqueous $0.1 \%$ formic acid solution: methanol $(50: 50 \mathrm{v} / \mathrm{v} \mathrm{pH}=3.8)$ pumped by a VDP-10A LC pump (Shimadzu, Japan), using a $1: 2$ postcolumn split. Solvents were first placed in ultrasound for 3 minutes and then put through a DGU-14A degassing system (Shimadzu, Japan). The system operated at pressures between 100 and 120 bar. The column and autosampler were kept at a temperature of $20^{\circ} \mathrm{C}$, and the injection volume was $20 \mu \mathrm{L}$.

The Quattro LC mass spectrometer (MS-MS) operated in positive electrospray ionization mode $(\mathrm{ES}+)$ and MRM dual-channel mode. The following parameters were used for the electrospray source: capillary voltage $3.00 \mathrm{kV}$, cone voltage $25.00 \mathrm{~V}$ for ranitidine and $30.00 \mathrm{~V}$ for propranolol, extractor voltage $3.00 \mathrm{~V}$, RF lens voltage $0.2 \mathrm{~V}$, source temperature $150^{\circ} \mathrm{C}$, cone gas flow $0.0 \mathrm{~L} / \mathrm{h}$, and desolvation gas flow $439 \mathrm{~L} / \mathrm{h}$. The following conditions were established for the quadrupoles of the Quattro LC mass spectrometer: LM1 resolution of 13.0, HM1 resolution of 13.0, ion 1 energy 0.2 , second hexapole input $5.0 \mathrm{~V}$, collision energy at $25.00 \mathrm{eV}$ for ranitidine and $17.00 \mathrm{eV}$ for propranolol, 5.0 output, LM2 resolution of 9.0, HM2 resolution 9.0, ion 2 energy 2.5, multiplier at $650 \mathrm{~V}, 0.5 \mathrm{~s}$ dwell time, and $0.1 \mathrm{~s}$ delay time.

2.3. Preparation of the Stock and Standard Solutions. The stock solutions of ranitidine and propranolol were prepared at a concentration of $0.5 \mathrm{mg} / \mathrm{mL}$ in methanol: water $(50: 50 \mathrm{v} / \mathrm{v})$. These solutions were used to prepare working solutions of ranitidine at concentrations of 30.00 , 50.00, 100.00, 500.00, 1000.00, 2000.00, 4000.00, and $5000.00 \mathrm{ng} / \mathrm{mL}$. The working solutions of propranolol were also prepared from stock solutions $(0.5 \mathrm{mg} / \mathrm{mL})$ at a concentration of $2000 \mathrm{ng} / \mathrm{mL}$. All solutions were placed in Falcon-type tubes. The tubes with the ranitidine solutions were protected from light with aluminum foil and stored in a freezer at $-20^{\circ} \mathrm{C}$. The other solutions were stored in a refrigerator at $+4^{\circ} \mathrm{C}$ and replaced daily.

2.4. Sample Preparation. Plasma samples were thawed at room temperature, homogenized by vortexing and centrifuged at $3400 \mathrm{rpm}$ for 4 minutes to precipitate materials suspended in the plasma. Waters Oasis 1-cc HLB solid phase extraction (SPE) cartridges and $30 \mathrm{mg}$ of adsorbent were used. These cartridges were previously conditioned with $1 \mathrm{~mL}$ of methanol and $1 \mathrm{~mL}$ of ultrapure water for activation of the drug binding sites.

More ever, $250 \mu \mathrm{L}$ of human plasma, $100 \mu \mathrm{L}$ of propranolol, and $500 \mu \mathrm{L}$ of ultrapure water were added to the SPE. The cartridge was then placed inside a clean test tube, and the cartridge-test tube combination was centrifuged at $3400 \mathrm{rpm}$ for 4 minutes for plasma elution and retention of the drug in the cartridge. Subsequently, the eluate was discarded, and the analytes were eluted with $1000 \mu \mathrm{L}$ of water:methanol solution $(20: 80 \mathrm{v} / \mathrm{v})$ with $0.1 \%$ of formic acid.

2.5. Analytical Curve. The analytical curve was prepared at concentration levels of 3.00, 5.00, 10.00, 50.00, 100.00, $200.00,400.00$, and $500.00 \mathrm{ng} / \mathrm{mL}$ of ranitidine. Also $250 \mu \mathrm{L}$ of human plasma, $100 \mu \mathrm{L}$ of each of the ranitidine solutions, $100 \mu \mathrm{L}$ of propranolol, and $400 \mu \mathrm{L}$ of ultrapure water were added to the SPE. Then, the sample preparation procedure was carried out. The sample quality controls (QCs) were prepared at concentrations of 3.00, 5.00, 200.0, and $400.00 \mathrm{ng} / \mathrm{mL}$ by spiking of blank plasma and the subsequent extraction process.

2.6. Extraction Recovery. The extraction method's recovery was determined by comparing ranitidine peak areas in samples that did not undergo the extraction process considering the extraction yield to be $100 \%$ and ranitidine peak areas in extracted samples at concentrations of 3.00, 5.00, 10.00, $50.00,100.00,200.00,400.00$, and $500.00 \mathrm{ng} / \mathrm{mL}$. For the internal standard, the extraction yield of replicates at a concentration of $200.00 \mathrm{ng} / \mathrm{mL}$ was determined.

2.7. Precision and Accuracy. The accuracy and precision of the method were determined by the extraction of eight samples containing the internal standard and the ranitidine analyte at concentrations 3.00,5.00, 200.00, and $400.00 \mathrm{ng} / \mathrm{mL}$, 
which were analyzed in replicates. This procedure was carried out intraday and between-day. The approval criterion for relative standard deviation (RSD) was $15 \%$.

2.8. Stability. Stability studies of ranitidine in plasma were performed under three conditions. First, stability was evaluated in three freezing cycles over $24 \mathrm{~h}$ at $-20^{\circ} \mathrm{C}$, followed by thawing. Subsequently, we evaluated the stability of ranitidine which was kept at room temperature for eight hours. Long-term stability was evaluated over a forty-day storage period. The acceptance criteria were a deviation from nominal concentration that was less than or equal to $15 \%$ and precision and accuracy less than or equal to $15 \%$.

The long-term stability of the standard drug solutions and the internal standard in the biological liquid at room temperature was evaluated after $12 \mathrm{~h}$ of preparation. These solutions were kept frozen at $-20^{\circ} \mathrm{C}$ for seven days before the analyses were carried out.

2.9. Biological Samples. The samples for bioequivalence tests were collected at the Cardiology Institute of Anápolis in the state of Goiás, Brazil. The study involved 24 volunteers and was conducted after approval of the study protocol by the Research Ethics Committee of the Universidade Federal de Goiás. Ranitidine was assessed for bioequivalence in $150 \mathrm{mg}$ tablet form.

Blood samples were collected with a total volume of $10 \mathrm{~mL}$. The blood was centrifuged and the plasma removed. Plasma samples were frozen at $-20^{\circ} \mathrm{C}$. The collection times were $15 \mathrm{~min}, 30 \mathrm{~min}, 45 \mathrm{~min}, 1: 00 \mathrm{~h}, 1: 15 \mathrm{~h}, 1: 30 \mathrm{~h}, 2: 00 \mathrm{~h}$, 2:30 h, 3:00 h, 4:00 h, 5:00 h, 6:00 h, 8:00 h, and 12:00 h. All samples collected were placed in test tubes containing 2 drops of heparin and then sent to the hospital analysis laboratory for plasma extraction.

\section{Results and Discussion}

3.1. Analyses by HPLC-MS-MS. The chromatographic method which was used allowed the ranitidine and the internal standard (propranolol) to elute with a resolution of 1.23 , with a retention time of $1.66 \mathrm{~min}$ for ranitidine and $2.13 \mathrm{~min}$ for the internal standard (Figure 2). The retention time obtained was similar to that found in a study by Zhang et al. [7] and was lower than that reported by Sun et al. [8] who obtained an elution time of 4.5 minutes for ranitidine.

Ranitidine and propranolol were identified through analysis of mass spectra obtained during the first and second ionizations of these analytes, as illustrated in Figure 3. Ranitidine underwent protonation in the first mass spectrometer, generating a quasimolecular ion $[\mathrm{M}+\mathrm{H}]^{+} \mathrm{m} / \mathrm{z}$ of 315.1. Through collision with argon gas, this generates the fragment (daughter ion) $\mathrm{m} / z 129.9$ determined in the second mass spectrometer. These mass spectra coincide with those obtained by Schellen et al. [9] and Kataoka et al. [10].

The quasimolecular ion generated by the internal standard (propranolol) $[\mathrm{M}+\mathrm{H}]^{+}$has $m / z$ of 260.3 which produces the fragment (daughter ion) $\mathrm{m} / z 116.1$ (Figure 3). These

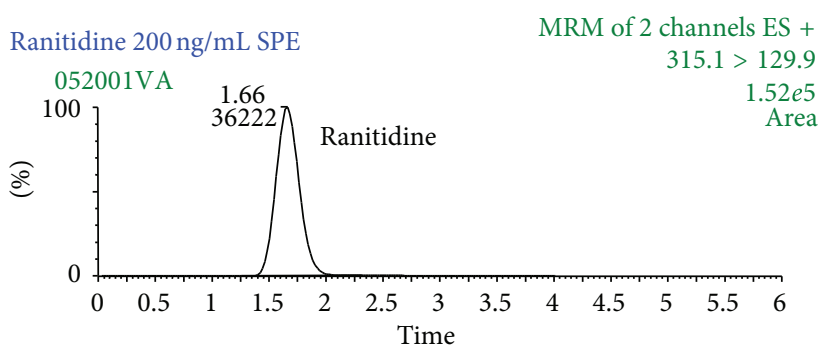

(a)

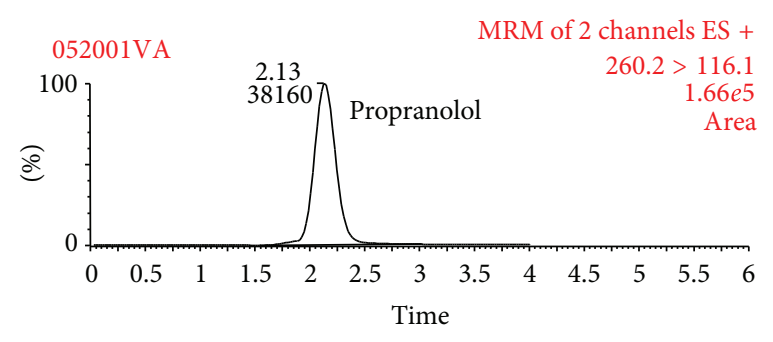

(b)

FIGURE 2: Total ion chromatogram (TIC) for ranitidine and propranolol.

spectra coincide with those obtained by Schellen et al. [9] and Xia et al. [11].

\section{Method Validation}

4.1. Selectivity/Specificity. Figure 4 shows chromatograms of normal blank plasma for ranitidine and the internal standard (propranolol) after the blank plasma samples were tested using the same procedure and under the same conditions as for sample analysis. As can be seen, no metabolites or interferents significant for the retention time of the drug or of the internal standard were found.

4.2. Analytical Curve. The mean determination coefficient of the calibration curve for ranitidine was 0.9989 . Linearity varied from 3.00 to $500.00 \mathrm{ng} / \mathrm{mL}$. Relative error values ranged from -6.60 to $8.66 \%$, which indicates an analytical curve of excellent linearity, broad linear dynamic range and adequate accuracy. This provides the quantification process with analytical reliability.

The lower limit of quantification (LLOQ) was $3.00 \mathrm{ng} / \mathrm{mL}$, with precision of $4.61 \%$ and accuracy of $100.62 \%$. The limit of detection (LOD) was $0.05 \mathrm{ng} / \mathrm{mL}$, a concentration whose signal-to-noise ratio was 3.98. The limit of quantification was lower than the LLOQ obtained by Zhang et al. [7] and Sun et al. [8] and near that obtained by Wang et al. [6] who used the protein precipitation method and obtained an LLOQ of $1 \mathrm{ng} / \mathrm{mL}$. Thus, the precision values are adequate and provide analytical reliability for LLOQ determination and validation.

4.3. Method Recovery. The absolute recovery of ranitidine was evaluated for eight concentrations $(n=6)$. The recoveries were $90.74 \pm 3.22 \%$ for a nominal concentration of $3.00 \mathrm{ng} / \mathrm{mL} ; 87.49 \pm 1.34 \%$ for $5.00 \mathrm{ng} / \mathrm{mL} ; 86.18 \pm 2.88 \%$ for 
Set

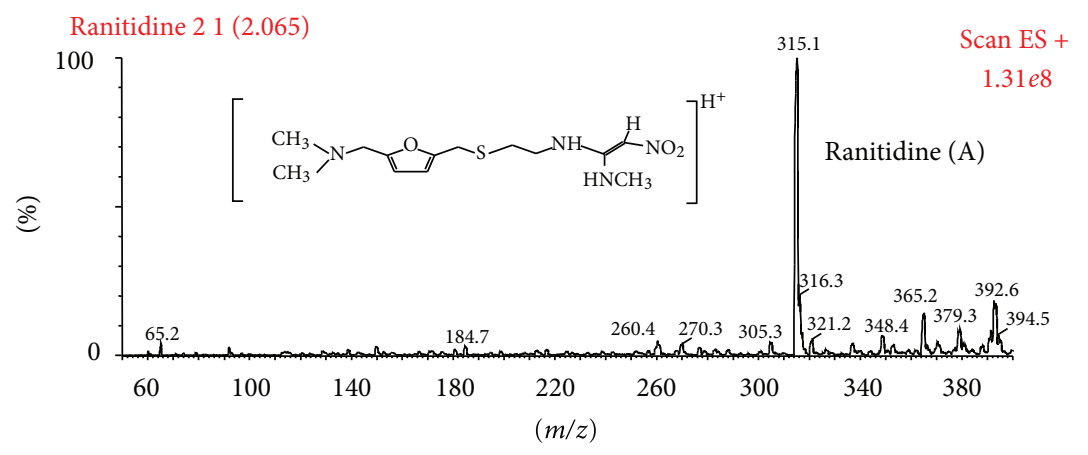

(a)

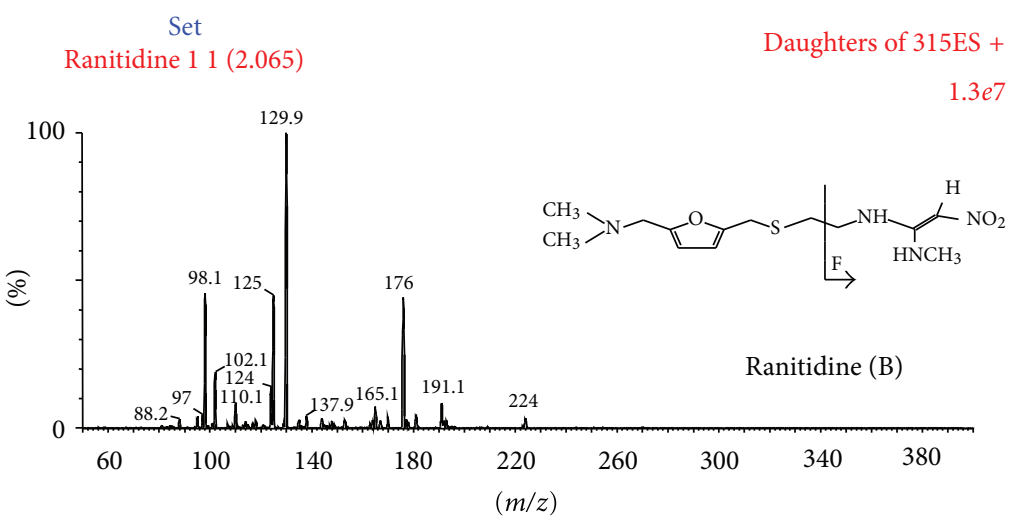

(b)

Set

Propranolol scan $2001(2.065)$

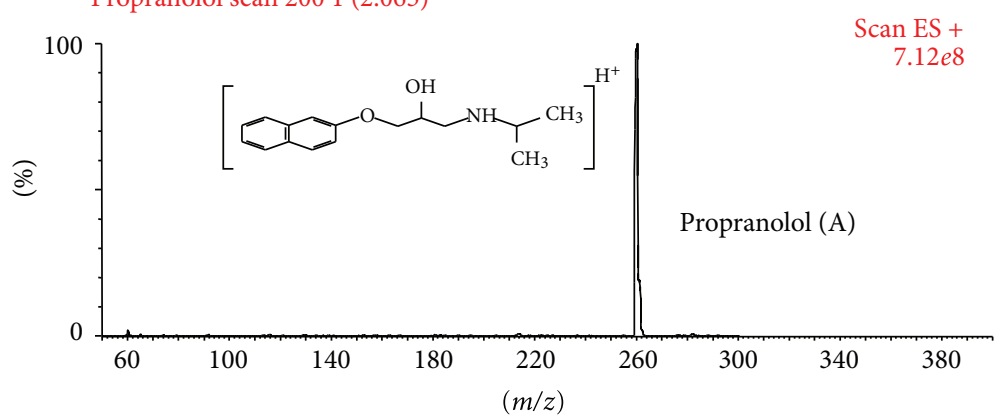

(c)

Set

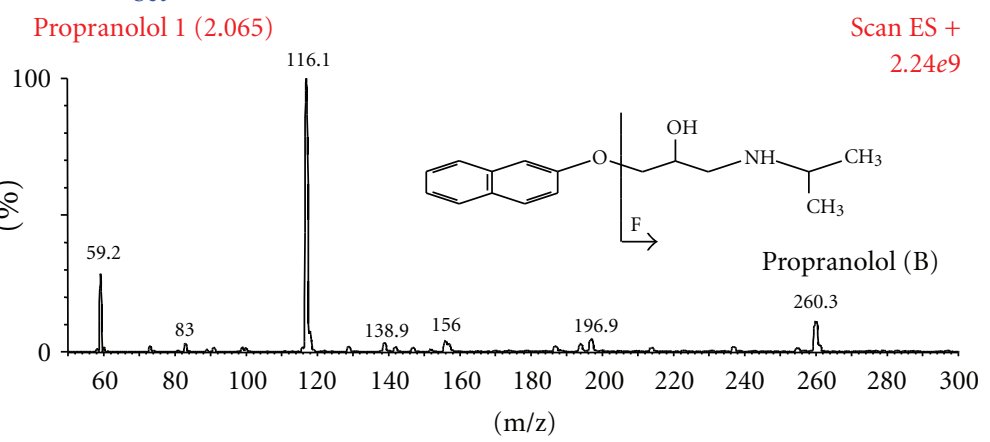

(d)

FIgURE 3: Mass spectrum of ranitidine and propranolol. (a) The first mass spectrometer. (b) The second mass spectrometer. 


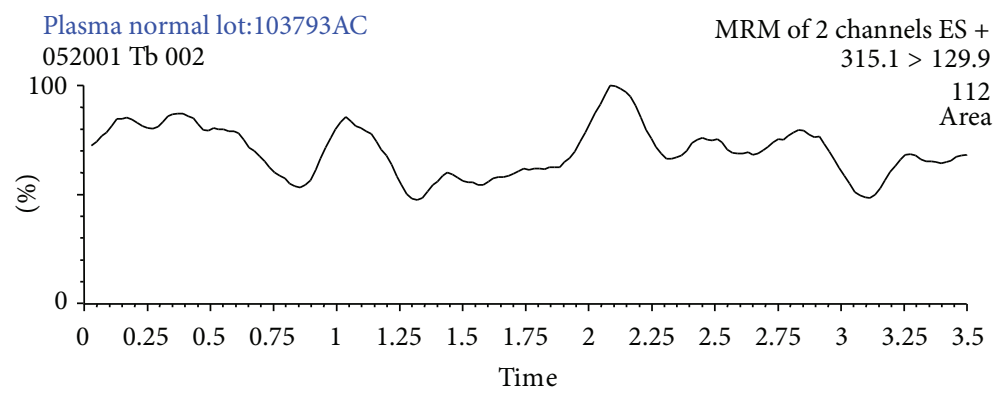

(a)

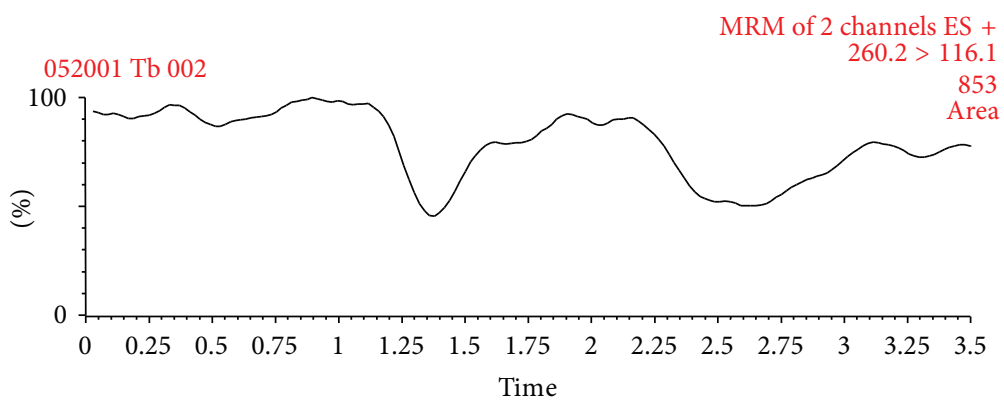

(b)

FIGURE 4: Chromatograms of normal blank plasma monitoring ranitidine and propranolol.

TABLE 1: Intraday and between-day precision and accuracy for the determination of ranitidine in plasma.

\begin{tabular}{|c|c|c|c|c|c|c|}
\hline \multirow{3}{*}{ Nominal } & \multicolumn{6}{|c|}{ Concentration $(\mu \mathrm{g} / \mathrm{mL}) n=8$} \\
\hline & \multicolumn{3}{|c|}{ Intraday } & \multicolumn{3}{|c|}{ Between-days } \\
\hline & Determined & RSD (\%) & Accuracy & Determined & RSD (\%) & Accuracy \\
\hline 3.00 & 2.79 & 9.75 & 93.2 & 2.92 & 4.04 & 97.3 \\
\hline 5.00 & 4.67 & 2.99 & 93.5 & 4.64 & 0.99 & 92.8 \\
\hline 200.00 & 197.19 & 3.29 & 98.6 & 202.43 & 2.41 & 101.2 \\
\hline 400.00 & 406.26 & 3.37 & 101.6 & 419.38 & 2.73 & 104.8 \\
\hline
\end{tabular}

$10.00 \mathrm{ng} / \mathrm{mL} ; 95.28 \pm 3.9 \%$ for $50.00 \mathrm{ng} / \mathrm{mL} ; 93.79 \pm 5.81 \%$ for $100.00 \mathrm{ng} / \mathrm{mL} ; 96.20 \pm 2.10 \%$ for $200.00 \mathrm{ng} / \mathrm{mL} ; 100.23 \pm$ $3.38 \%$ for $400.00 \mathrm{ng} / \mathrm{mL}$; $105.44 \pm 10.1 \%$ for $500 \mathrm{ng} / \mathrm{mL}$. The recovery of the internal standard was $89.4 \pm 4.37 \%$, and the mean recovery of ranitidine in plasma by SPE was $94.41 \%$, a result that demonstrates the effectiveness of the method in bioequivalence studies.

4.4. Accuracy and Precision. The intra-day and betweenday accuracy and precision results for the determination of ranitidine in human plasma are presented in Table 1 . The results indicate that the proposed method provides intraday and between-day accuracy and precision within the parameters desirable for an analytical method for the study of drug bioequivalence.

4.5. Stability. Table 2 presents data on the stability of ranitidine and propranolol under different conditions. The acceptance criteria were a deviation from the nominal concentration and precision less than or equal to $15 \%$. Neither ranitidine nor propranolol was degraded by the influence of various storage temperature fluctuations, which ensures that these samples may undergo several cycles of freezing and thawing with no loss in analyte concentration. In addition, the drugs are not degraded during the period in which the sample remains in the equipment to be analyzed. The longterm stability assessment has shown that the samples remain stable over the forty-day period.

4.6. Pharmacokinetic Study. The method was effectively applied in the bioequivalence study. Figure 5 displays mean plasma concentration of ranitidine versus time, comparing the test drug $(\mathrm{T})$ to the reference $(\mathrm{R})$, for the 24 volunteers who participated in the study. The test ranitidine showed a profile similar to that of the reference drug, with a maximum plasma concentration $\left(C_{\max }\right)$ of $90.0 \mathrm{ng} / \mathrm{mL}$ occurring at $1.8 \mathrm{~h}$.

For some volunteers, there were two plasma concentration peaks for ranitidine. Several other studies have also reported this [12-14]. Some authors attribute this finding 
TABLE 2: Stability of ranitidine and propranolol under different conditions $(n=5)$.

\begin{tabular}{|c|c|c|c|}
\hline \multirow{2}{*}{ Conditions } & \multicolumn{3}{|c|}{ Concentration (ng/mL) } \\
\hline & Drug & Nominal & Determined mean \\
\hline \multirow{2}{*}{ Freezing and thawing cycles } & \multirow{2}{*}{ Ranitidine } & 5.06 & $5.46 \pm 1.39 \%$ \\
\hline & & 407.13 & $429.99 \pm 1.17 \%$ \\
\hline \multirow{3}{*}{ Room temperature for $8 \mathrm{~h}$} & \multirow{2}{*}{ Ranitidine } & 4.97 & $5.05 \pm 2.63 \%$ \\
\hline & & 411.44 & $423.99 \pm 2.01 \%$ \\
\hline & Propranolol & 214 & $195 \pm 7.06 \%$ \\
\hline \multirow{2}{*}{ Storage at $-20^{\circ} \mathrm{C}$ for 40 days } & \multirow{2}{*}{ Ranitidine } & 4.8 & $5.28 \pm 3.23 \%$ \\
\hline & & 390.79 & $400.33 \pm 4.05 \%$ \\
\hline \multirow{3}{*}{ Standard solutions for $12 \mathrm{~h}$} & \multirow{2}{*}{ Ranitidine } & 5.00 & $5.15 \pm 0.87 \%$ \\
\hline & & 404.66 & $429.78 \pm 1.89 \%$ \\
\hline & Propanolol & 185.2 & $181.2 \pm 7.06$ \\
\hline
\end{tabular}

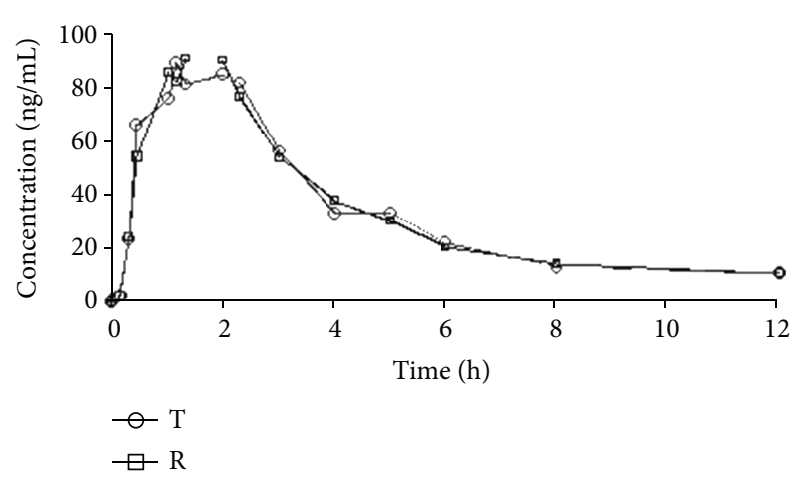

FIGURE 5: Mean plasma concentration of ranitidine versus time for test $(T)$ and reference $(R)$ products.

to the mechanism of enterohepatic recirculation [15], while others attribute it to the existence of multiple drug binding sites along the gastrointestinal tract [16].

\section{Conclusions}

The analytical method for determining ranitidine in human plasma using SPE and LC-MS/MS offers high recovery, excellent linearity, accuracy, and precision, and a lower limit of quantification that is adequate for checking the remaining plasma concentration of ranitidine. In addition, the procedure offers fast execution and chromatographic analysis, with excellent resolution.

This methodology is appropriate for assessing the stability of ranitidine under various conditions. Ranitidine was stable in all the processes used to assess the stability of these drugs in biological matrices. Analysis of these drugs is therefore possible after long periods of adequate storage at $-20^{\circ} \mathrm{C}$.

Thus, the method is fully applicable to bioequivalence and bioavailability studies of ranitidine.

\section{Conflict of Interests}

The authors declare that they do not have a direct financial relation with Merck and Millipore (Milli-Q).

\section{Acknowledgments}

The authors acknowledge MCT, FINEP, FUNAPE, and CNPq for the financial support, and CAPES CNPq for the productivity fellowship to N. R. A. Filho (Process no. 309832/2010$1)$.

\section{References}

[1] United States Pharmacopeial Convention, U.S. Pharmacopeia \& National Formulary, National Publishing, Philadelphia, Pa, USA, 24th edition, 2000.

[2] M. A. Rocha Júnior, "Histamina e Anti-histamínicos," in Farmacologia, P. Silva, Ed., p. 54, Guanabara Koogan, Rio de Janeiro, Brazil, 5th edition, 1998.

[3] J. Dawson, D. A. Richards, and R. Stables, "Ranitidinepharmacology and clinical use," Journal of Clinical and Hospital Pharmacy, vol. 8, no. 1, pp. 1-13, 1983.

[4] D. Zendelovska and T. Stafilov, "Development of an HPLC method for the determination of ranitidine and cimetidine in human plasma following SPE," Journal of Pharmaceutical and Biomedical Analysis, vol. 33, no. 2, pp. 165-173, 2003.

[5] T. G. Do Nascimento, E. De Jesus Oliveira, and R. O. Macêdo, "Simultaneous determination of ranitidine and metronidazole in human plasma using high performance liquid chromatography with diode array detection," Journal of Pharmaceutical and Biomedical Analysis, vol. 37, no. 4, pp. 777-783, 2005.

[6] L. Wang, L.-M. Zhao, Y.-T. Sun, and J.-K. Gu, "Rapid determination of ranitidine in human plasma by liquid chromatographytandem mass spectrometry and its application to a clinical pharmacokinetic study," Chemical Research in Chinese Universities, vol. 26, no. 6, pp. 910-914, 2010.

[7] Y. Zhang, N. Mehrotra, N. R. Budha, M. L. Christensen, and B. Meibohm, "A tandem mass spectrometry assay for the simultaneous determination of acetaminophen, caffeine, phenytoin, ranitidine, and theophylline in small volume pediatric plasma specimens," Clinica Chimica Acta, vol. 398, no. 1-2, pp. 105-112, 2008.

[8] X. Sun, Y. Tian, Z. Zhang, and Y. Chen, "A single LC-tandem mass spectrometry method for the simultaneous determination of four $\mathrm{H}_{2}$ antagonists in human plasma," Journal of Chromatography $B$, vol. 877, no. 31, pp. 3953-3959, 2009. 
[9] A. Schellen, B. Ooms, D. Van De Lagemaat, R. Vreeken, and W. D. Van Dongen, "Generic solid phase extractionliquid chromatography-tandem mass spectrometry method for fast determination of drugs in biological fluids," Journal of Chromatography B, vol. 788, no. 2, pp. 251-259, 2003.

[10] H. Kataoka, H. L. Lord, and J. Pawliszyn, "Automated in-tube solid-phase microextraction-liquid chromatographyelectrospray ionization mass spectrometry for the determination of ranitidine," Journal of Chromatography B, vol. 731, no. 2, pp. 353-359, 1999.

[11] Y. Q. Xia, R. Bakhtiar, and R. B. Franklin, "Automated online dual-column extraction coupled with teicoplanin stationary phase for simultaneous determination of (R)- and (S)propranolol in rat plasma using liquid chromatography-tandem mass spectrometry," Journal of Chromatography B, vol. 788, no. 2, pp. 317-329, 2003.

[12] M. A. Campanero, A. Lopez-Ocariz, E. García-Quetglás, B. Sádaba, and A. De La Maza, "Rapid determination of ranitidine in human plasma by high-performance liquid chromatography," Chromatographia, vol. 47, no. 7-8, pp. 391-395, 1998.

[13] G. Mullersman and H. Derendorf, "Rapid analysis of ranitidine in biological fluids and determination of its erythrocyte partitioning," Journal of Chromatography, vol. 381, no. 2, pp. 385-391, 1986.

[14] K. S. Reynolds, M. H. Song, W. D. Heizer, C. B. Burns, D. A. Sica, and K. L. R. Brouwer, "Effect of pancreatico-biliary secretions and GI transit time on the absorption and pharmacokinetic profile of ranitidine in humans," Pharmaceutical Research, vol. 15, no. 8, pp. 1281-1285, 1998.

[15] R. Miller, "Pharmacokinetics and bioavailability of ranitidine in humans," Journal of Pharmaceutical Sciences, vol. 73, no. 10, pp. 1376-1379, 1984.

[16] P. Schaiquevich, A. Niselman, and M. Rubio, "Comparison of two compartmental models for describing ranitidine's plasmatic profiles," Pharmacological Research, vol. 45, no. 5, pp. 399-405, 2002. 

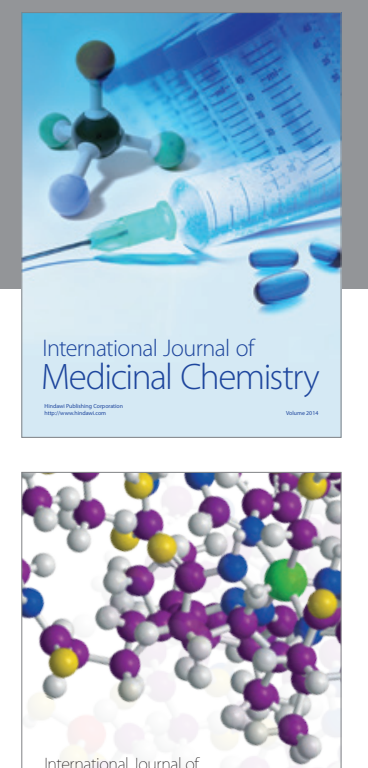

\section{Carbohydrate} Chemistry

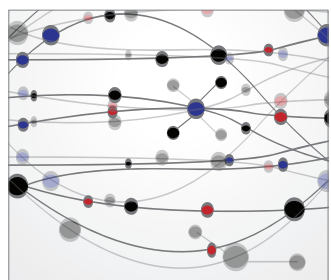

The Scientific World Journal
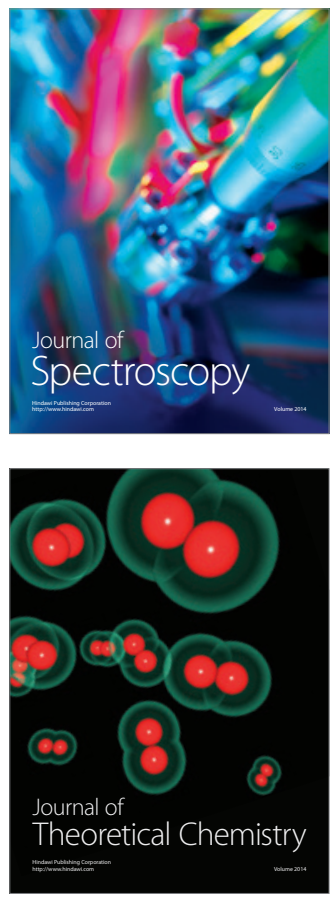
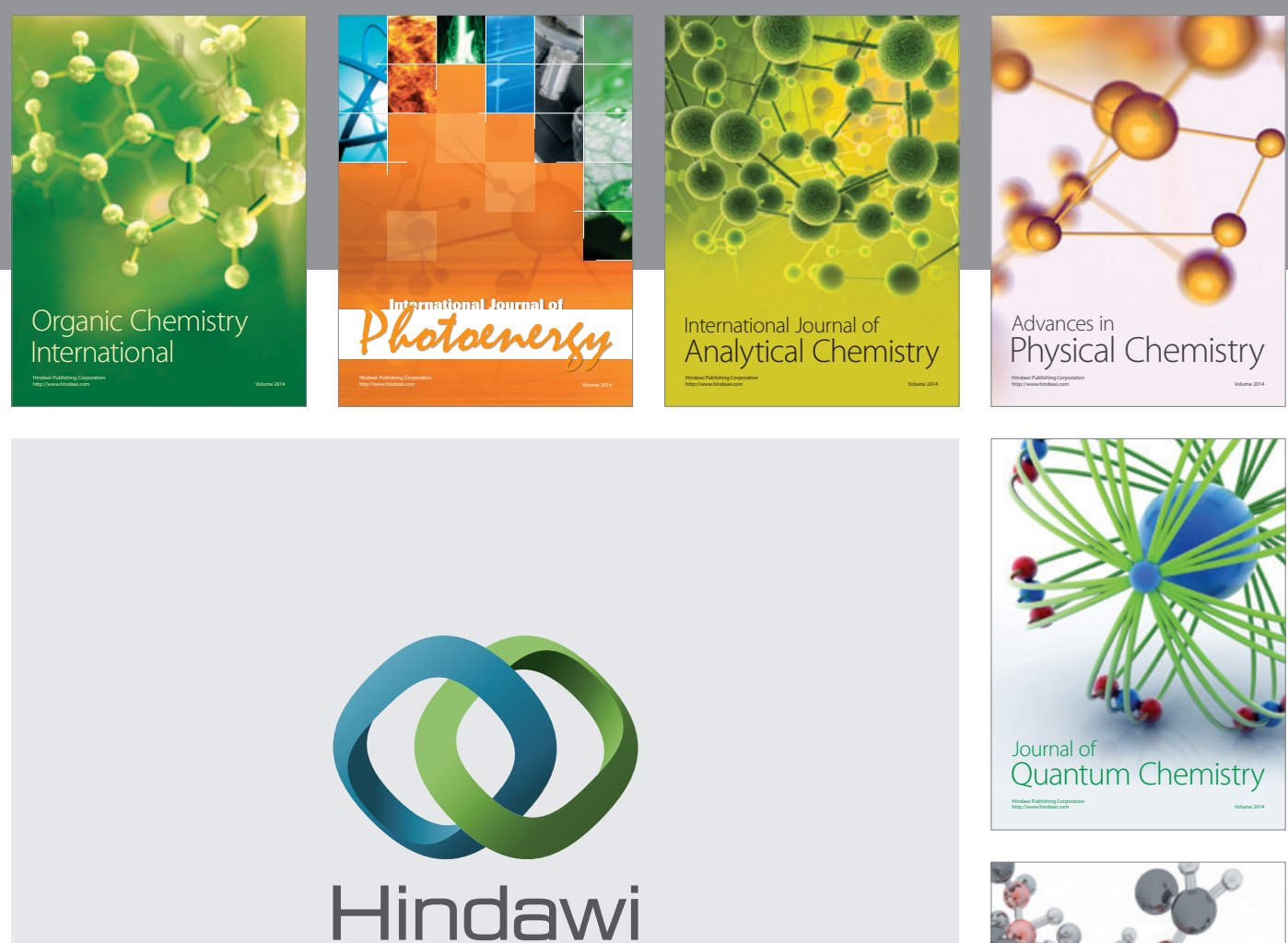

Submit your manuscripts at

http://www.hindawi.com

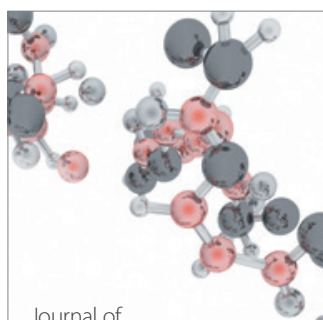

Analytical Methods

in Chemistry

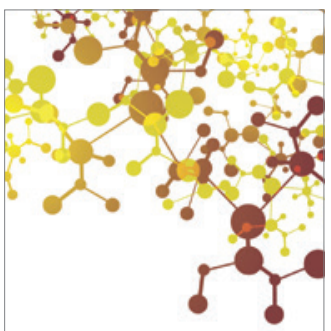

Journal of

Applied Chemistry

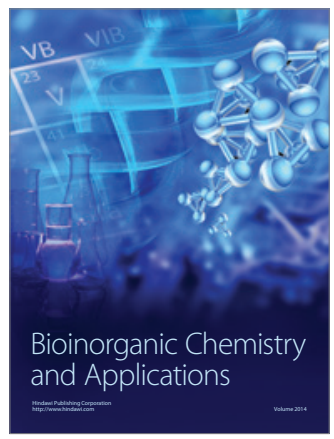

Inorganic Chemistry
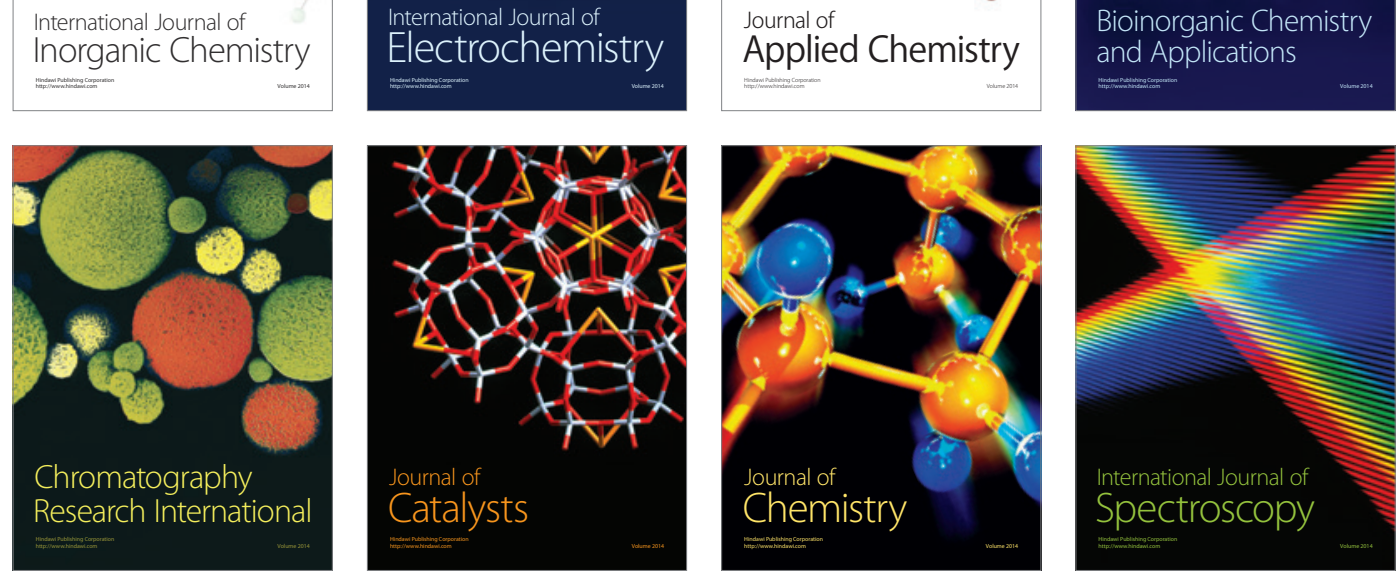